\title{
Voltage Stability Control of Wind Farm Using STATCOM
}

\author{
Abhishek Walia*, Nipun Aggarwal** \\ *(M.Tech Scholar, EE, Indus Institute of Engineering \& Technology, Jind, Haryana, India \\ Email : aa189319@gmail.com) \\ **(Assistant Professor, Department of Electrical Engineering, Indus Institute of Engineering \& Technology, \\ Jind, HR, India. \\ Corresponding author: Abhishek Walia
}

\begin{abstract}
The conversion of wind energy into electrical power generation is very useful, important and economical. Due to injection of wind power in electrical grid system, many power quality issues raisedsuch as reliability, harmonic, distortion and voltage level. In this paper focused on removing harmonics and maintain voltage level. The proposed scheme of static synchronous compensator (STATCOM) is connected at point of common coupling (PCC) with battery energy storage system to improve power quality. The STATCOM control scheme is simulated using MATLAB/SIMULINK to maintain power (both active and reactive power) and terminal voltage. The proposed scheme maintains voltage level, remove harmonic \&distortion and free main supply source from reactive power demand of load in power system.

Keywords: Static Synchronous Compensator (STATCOM), Point of Common Coupling (PCC), Wind Energy, Power Stability.
\end{abstract}

\section{INTRODUCTION}

The energy conservation and use of energy source are the key paradigms of sustainable energy system. To meet our energy needs, use renewable energy sources like wind, tidal, biomass, cogeneration, hydro etc. The need to integrate the renewable energy like wind energy into power system is to make it possible to minimize the environmental impact on conventional plant [1]. The wind energy system is integrated into exciting power system presents technical challenges and voltage regulations, stability and power quality problems. The power quality is an important factor and it's greatly affects transmission and distribution system. The issue of power quality is of great importance to the wind turbine [2]. There have been recent developments in field of wind energy.

The individual units can be of large capacity of $2 \mathrm{MW}$, feeding into distribution networks, particularly with customers connected in close proximity [3]. During the normal operation, wind turbine produces a continuous variable output power. The reasons behind these variations are effect of turbulence, wind shear, tower shadow and control system. The power quality issues are voltage sag, voltage swell, and harmonic distortion, under voltage, transients, noise, interruptions, notching, short circuit and voltage flickering [4]. The induction generator requiresreactive power for magnetization. So the active power generated by an induction generator is varied due to wind, absorbed reactive power and terminal voltage affected. To proper control of active power under normal operating conditions, a proper control scheme in wind energy system is required [5,6]. A STATCOM based control system has been used for improving power quality which manages the power level with commercial wind turbines. The proposed control scheme for power quality improvement has following objectives:

(i) Unity power factor

(ii) Reactive power

(iii) To achieve fast dynamic response

\section{STATCOM}

Static synchronous compensator (STATCOM) is a shunt connected controller. This is also an advanced version of SVC and more than a static condenser. The STATCOM has similar characteristics as a synchronous condenser. As an electronic device, it has no inertia. It is superior to synchronous condenser, such as better dynamics, a lower investment cost, a lower operating and maintenance costs. The STATCOM controls voltage level of connected bus by adjusting voltage and angle of internal voltage source. Fig.1 shows STATCOM with characteristics [7]. 

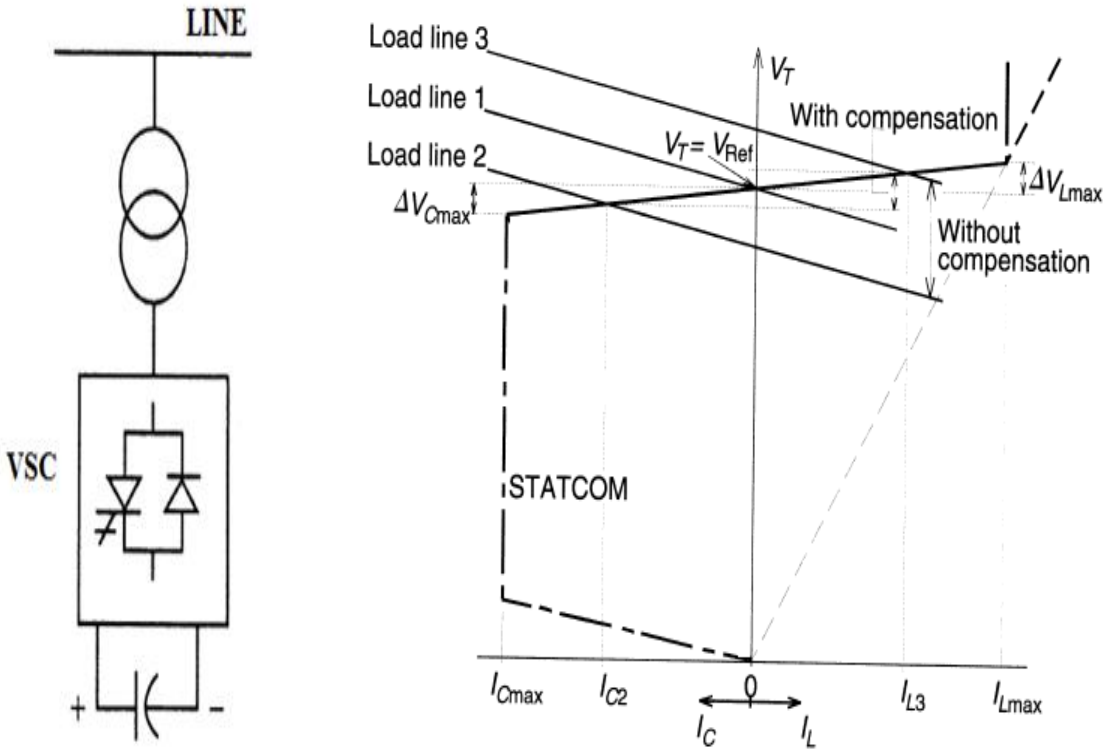

Fig. 1 shows STATCOM with Characteristics

STATCOM are based on voltage source converter (VSC) and utilize either Gate turn off thyristor (GTO) or Isolated gate bipolar transistor (IGBT) devices. AS a VSC, it compensates the active and reactive power of system by conversion of DC input voltage into AC output voltage. The STATCOM is a very fast acting, electronic equipment oaf asynchronous condenser. If STATCOM voltage, Vs is greater than bus voltage Es, then leading or capacitive VARs are produced. If $\mathrm{Vs}$ is smaller than Es, then lagging or inductive VARs are produced $[8,9]$.

\section{POWER QUALITY IMPROVEMENT}

The STATCOM based current control voltage source inverter injects the current into grid in such a way that that the source current are harmonic free and their phase angle with respect to source voltage has a desired value [10]. Due to injected current, the reactive and harmonic part of load and induction generator current will cancel out, thus it improve power quality and power factor of network. STATCOM has a natural tendency to compensate for changes in system voltage, even without control action, but its low stored energy means it can do this much more rapidly [11-13]. The proposed grid connected system is implemented for power quality improvement at point of common coupling (PCC) as shown in Fig. 2 [14].

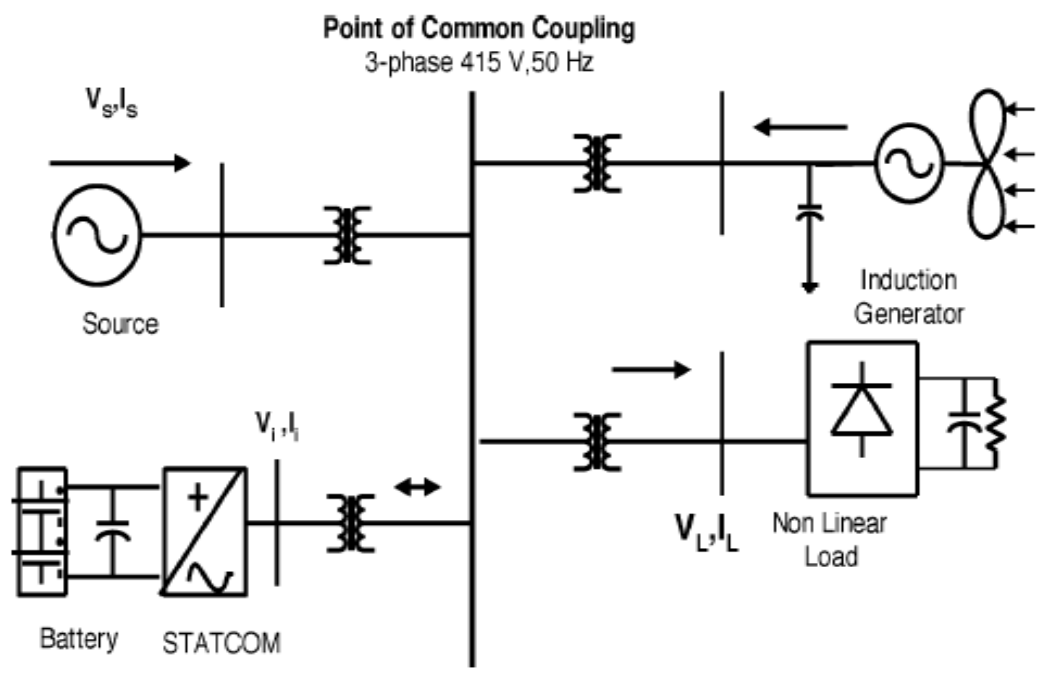


Fig. 2 Grid connected system for power quality improvement

\section{SIMULATION RESULTS}

The STATCOM control scheme for grid connected wind energy generation system for power quality improvement is simulated by MATLAB / SIMULINK in power system block set. The pitch angle controller make the angle of turbine blade to adjust such that speed of rotation at every velocity of wind is maintained constant. The shunt connected STATCOM with battery energy storage is connected with interface of induction generator and non- linear load at PCC in grid system. The current control strategies includes in control scheme that defines the functional operation of STATCOM in power system. To maintain power quality norms in grid system, output of STATCOM is varied according to control strategy.

The MATLAB simulation model comprise of major components as shown in Fig.3 are following:

(a) Power source of voltage $415 \mathrm{~V}, 50 \mathrm{~Hz}$

(b) Grid connected self excited induction generator

(c) a non-linear load

(d) a STATCOM

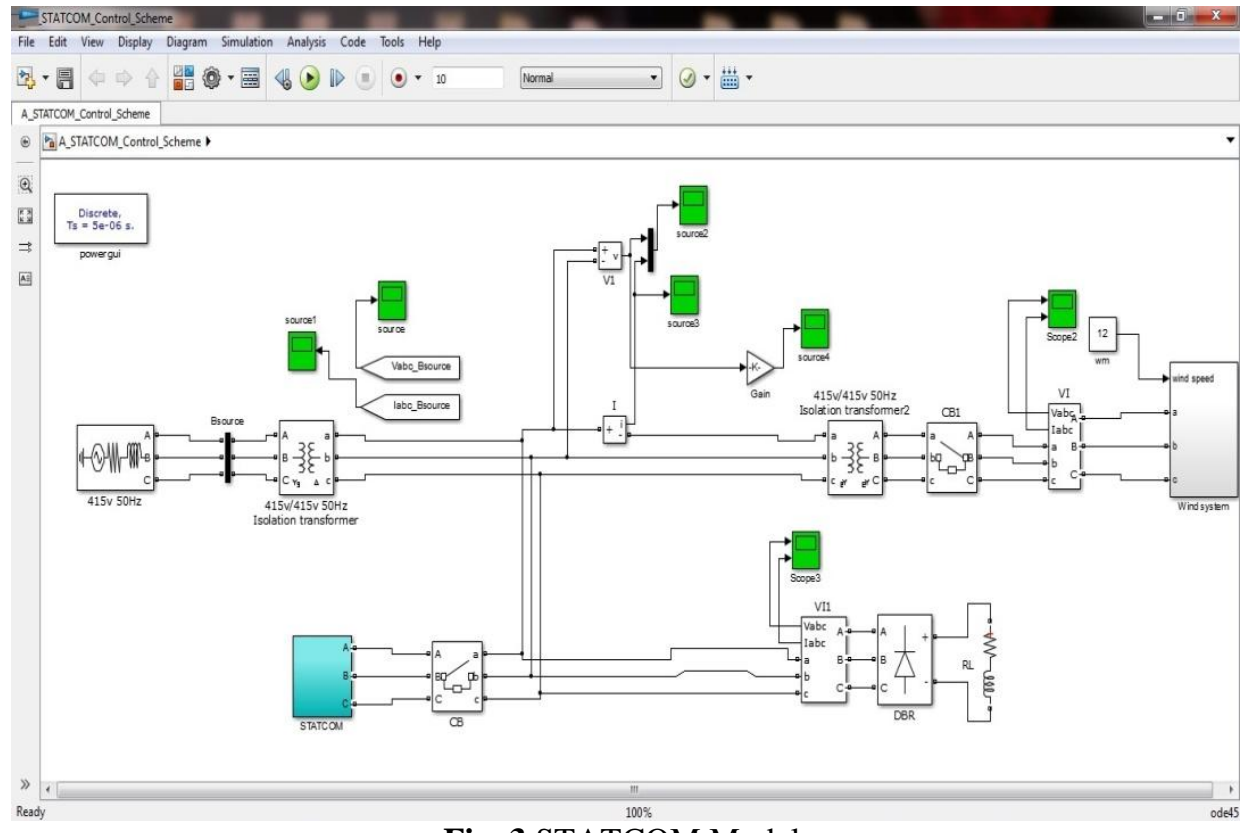

Fig. 3 STATCOM Model

A grid voltage and current without STATCOM waveform is shown in Fig. 4. 


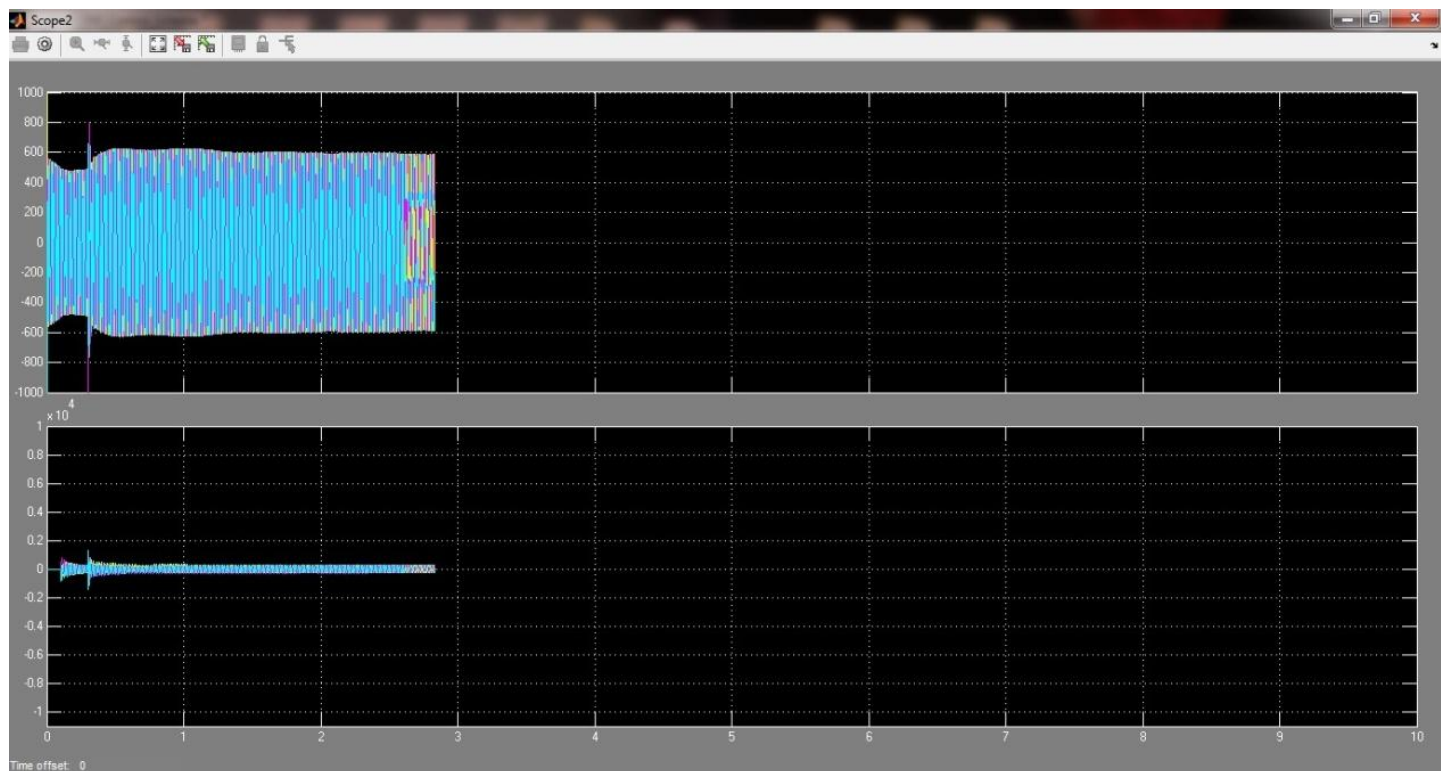

Fig. 4 Grid voltage and current without STATCOM

In this Fig. 4, without incorporation of STATCOM it gives low voltage of around $0.02 \mathrm{pu}$ where the actual value should be $0.0301 \mathrm{pu}$ and this is obtained by incorporation of STATCOM in the circuit and improved \& controlled power quality. The result is shown in Fig. 5 which shows Grid voltage and current with STATCOM.

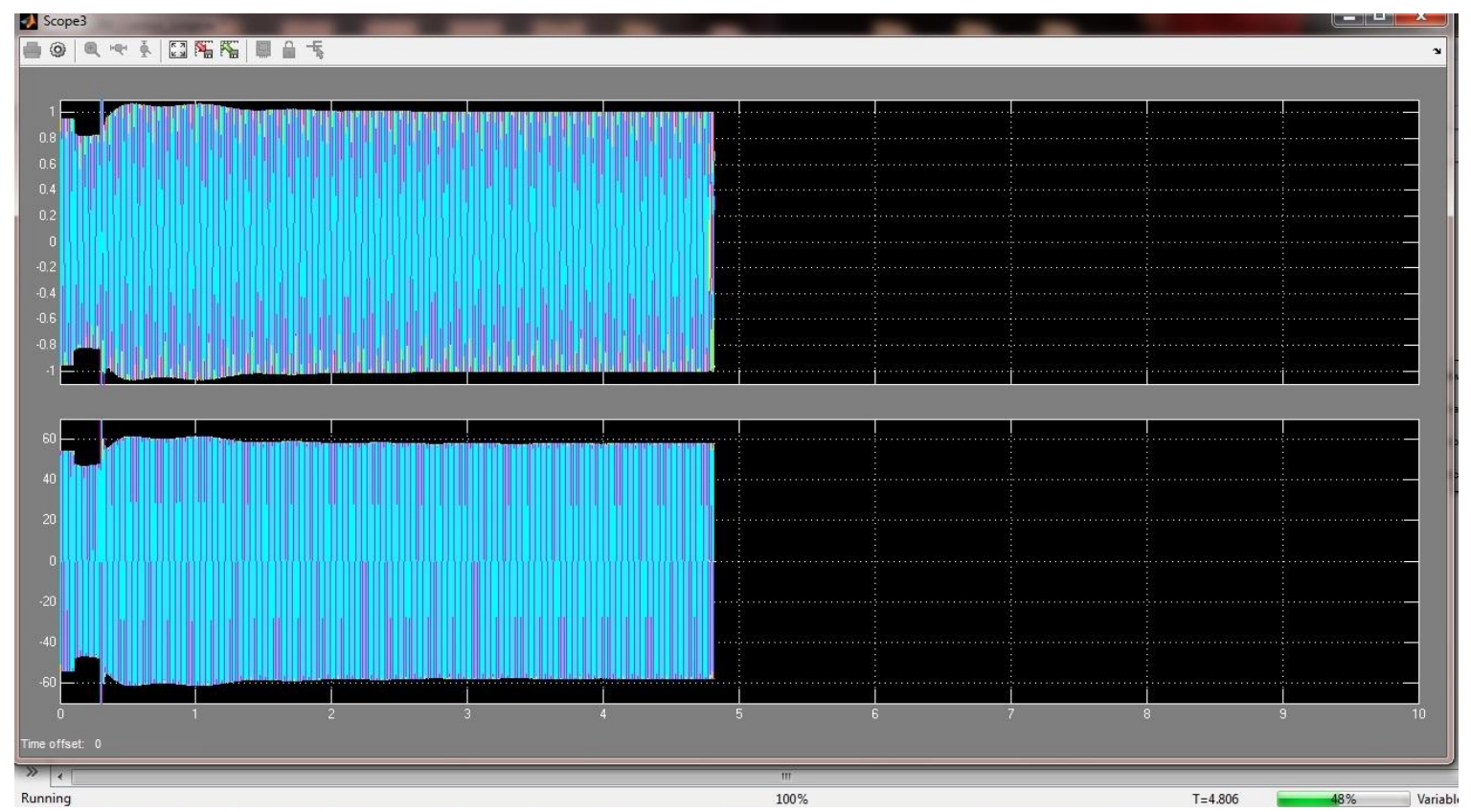

fig.5 Grid voltage and current with STATCOM

\section{CONCLUSION}

The present paper shows the STATCOM based control scheme for power quality improvement in grid connected wind plant with non-linear load. The operation of this scheme for power quality is simulated by STATCOM in MATLAB/SIMULINK. A grid connected SEIG decrease the voltage level at PCC due to absorption of reactive power and non-linear load increases harmonics at PCC, results voltage waveform distorted and provides poor quality at STATCOM. The STATCOM improves the quality of power at PCC, which reduces harmonics and maintain voltage by providing reactive power to the system. Thus proposed scheme fulfill the power quality requirements and maintains grid voltage free from distortion and harmonics in power system. 


\section{REFERENCES}

[1]. A. Sannino, "Global power systems for sustainable development," in IEEE General Meeting, Denver, CO, Jun. 2004.

[2]. K. S. Hook, Y. Liu, and S. Atcitty, "Mitigation of the wind generationintegration related power quality issues by energy storage," EPQU J., vol. XII, no. 2, 2006.

[3]. R. Billinton and Y. Gao, "Energy conversion system models for adequacyassessment of generating systems incorporating wind energy," IEEE Trans. on E. Conv., vol. 23, no. 1 , pp. 163-169, 2008, Multistate.

[4]. S. W. Mohod and M. V. Aware, "Power quality issues \&it's mitigation technique in wind energy conversion," in Proc. Of IEEE Int. Conf. Quality Power \& Harmonic, Wollongong, Australia, 2008.

[5]. J. Manel, "Power electronic system for grid integration of renewable energy source: A survey," IEEE Trans. Ind. Electron., vol. 53, no. 4, pp. 1002-1014, 2006, Carrasco.

[6]. C. Han, A. Q. Huang, M. Baran, S. Bhattacharya, and W. Litzenberger, "STATCOM impact study on the integration of a large wind farm into a weak loop power system," IEEE Trans. Energy Conv., vol. 23, no. 1,pp. 226-232, Mar. 2008.

[7]. N. G. Hingorani and L. Gyugyi, Understanding FACTS: Concepts and Technology of Flexible AC Transmission Systems. New York: IEEE Press, 2000.

[15]. (PEDES), Delhi, Dec. 2006.
[8]. M. I. Milands, E. R. Cadavai, and F. B. Gonzalez, "Comparison of control strategies for shunt active power filters in three phase four wire system," IEEE Trans. Power Electron., vol. 22, no. 1, pp. 229-236, Jan. 2007.

[9]. K.R. Padiyar, "Facts controllers in power transmission and distribution", new age international publication.

[10]. Alok Kumar Mohanty, Amar Kumar Barik, "Power System Stability Improvement Using FACTS Devices" International Journal of Modern Engineering Research (IJMER), Vol.1, Issue.2, pp-666-672 ISSN: 2249-6645.

[11]. J. Manel, "Power electronic system for grid integration of renewable energy source: A survey," IEEE Trans. Ind. Electron., vol. 53, no. 4, pp. 1002-1014, 2006, Carrasco.

[12]. M. Tsili and S. Papathanassiou, "A review of grid code technology requirements for wind turbine," Proc. IET Renew. power gen., vol. 3, pp. 308-332, 2009.

[13]. S. Rajesh Rajan, "Power quality improvement in grid connected in grid connected wind energy system using STATCOM", IJAREEIE vol. 2 issue 3, march 2013.

[14]. S. W. Mohod and M. V. Aware, "Grid power quality with variable speed wind energy conversion," in Proc. IEEE Int. Conf. Power Electronic Drives and Energy System

International Journal of Engineering Research and Applications (IJERA) is UGC approved Journal with S1. No. 4525, Journal no. 47088. Indexed in Cross Ref, Index Copernicus (ICV 80.82), NASA, Ads, Researcher Id Thomson Reuters, DOAJ.

Abhishek Walia. "Voltage Stability Control of Wind Farm Using STATCOM." International Journal of Engineering Research and Applications (IJERA) 7.7 (2017): 71-75. 